\title{
Choline acts during preimplantation development of the bovine embryo to program postnatal growth and alter muscle DNA methylation
}

Estrada-Cortés, Eliab; Ortiz, William; Rabaglino, Maria B.; Block, Jeremy; Rae, Owen; Jannaman, Elizabeth A.; Xiao, Yao; Hansen, Peter J.

\section{Published in:}

FASEB Journal

Link to article, DOI:

10.1096/fj.202100991R

Publication date:

2021

Document Version

Publisher's PDF, also known as Version of record

Link back to DTU Orbit

Citation (APA):

Estrada-Cortés, E., Ortiz, W., Rabaglino, M. B., Block, J., Rae, O., Jannaman, E. A., Xiao, Y., \& Hansen, P. J. (2021). Choline acts during preimplantation development of the bovine embryo to program postnatal growth and alter muscle DNA methylation. FASEB Journal, 35(10), [e21926]. https://doi.org/10.1096/fj.202100991R

\section{General rights}

Copyright and moral rights for the publications made accessible in the public portal are retained by the authors and/or other copyright owners and it is a condition of accessing publications that users recognise and abide by the legal requirements associated with these rights.

- Users may download and print one copy of any publication from the public portal for the purpose of private study or research.

- You may not further distribute the material or use it for any profit-making activity or commercial gain

- You may freely distribute the URL identifying the publication in the public portal 


\title{
Choline acts during preimplantation development of the bovine embryo to program postnatal growth and alter muscle DNA methylation
}

\author{
Eliab Estrada-Cortés ${ }^{1,2}$ (1) | William Ortiz $^{1}$ (D) | Maria B. Rabaglino ${ }^{3}$ (D) | \\ Jeremy Block ${ }^{4}$ (i) | Owen Rae ${ }^{5}$ | Elizabeth A. Jannaman' ${ }^{1}$ | Yao Xiao' ${ }^{1}$ | \\ Peter J. Hansen ${ }^{1}$ (D) \\ ${ }^{1}$ Department of Animal Sciences and D.H. Barron Reproductive and Perinatal Biology Research Program, and Genetics Institute, University of \\ Florida, Gainesville, Florida, USA \\ ${ }^{2}$ Campo Experimental Centro Altos de Jalisco, Instituto Nacional de Investigaciones Forestales, Agrícolas y Pecuarias, Tepatitlán de Morelos, Mexico \\ ${ }^{3}$ Quantitative Genetics, Bioinformatics and Computational Biology Group, Department of Applied Mathematics and Computer Science, Technical \\ University of Denmark, Lyngby, Denmark \\ ${ }^{4}$ Department of Animal Science, University of Wyoming, Laramie, Wyoming, USA \\ ${ }^{5}$ Department of Large Animal Clinical Sciences, College of Veterinary Medicine, University of Florida, Gainesville, Florida, USA
}

\section{Correspondence}

Peter J. Hansen, Department of Animal Sciences and D.H. Barron Reproductive and Perinatal Biology Research Program, and Genetics Institute, University of Florida, PO Box 110910, Gainesville, FL 32611-0910, USA.

Email: pjhansen@ufl.edu

\section{Present address}

William Ortiz, Departamento de Nutrição Animal do Grupo Matsuda, Rodovia Raposo Tavares, SP 270, Km 575, Álvares Machado, SP, Brazil

Maria B. Rabaglino, School of Agriculture and Food Science, University College Dublin, Belfield, Dublin 4, Ireland

Elizabeth A. Jannaman, CCRM Colorado, Lone Tree, Colorado, USA

Yao Xiao, Institute of Animal Science and Veterinary Medicine, Shandong Academy of Agricultural Sciences, Jinan, Shandong 250100, China

\begin{abstract}
The preimplantation period of embryonic development can be a key window for programming of postnatal development because extensive epigenetic remodeling occurs during this time. It was hypothesized that modification of one-carbon metabolism of the bovine embryo by addition of the methyl-donor choline to culture medium would change postnatal phenotype through epigenetic modification. Embryos produced in vitro were cultured with $1.8 \mathrm{mM}$ choline chloride or control medium. Blastocysts were transferred into females and pregnancy outcomes and postnatal phenotype of the resultant calves determined. Exposure of embryos to choline increased gestation length and calf birth weight. Calves derived from choline-treated embryos were also heavier at weaning and had increased ratio of body weight to hip height than control calves. Choline altered muscle DNA methylation of calves 4 months after birth. A total of 670 of the $8149 \mathrm{CpG}$ examined were differentially methylated, with the predominant effect of choline being hypomethylation. Among the genes associated with differentially methylated CpG were ribosomal RNAs and genes in AMPK, mTOR, integrin, and BEX2 canonical pathways and cellular functions involved in growth and proliferation.
\end{abstract}

\footnotetext{
Abbreviations: COC, cumulus-oocyte complexes; DMC, differentially-methyalted cytosine; GnRH, gonadotropin releasing hormone; HEPES-TALP, HEPES-buffered Tyrode's albumin-lactate-pyruvate; IVF-TALP, in vitro fertilization Tyrode's albumin-lactate-pyruvate; OPU, ovum pick-up. 


\section{Funding information}

Research was supported by USDA-NIFA 2020-67015-30821, LE “Red” Larson Endowment, Florida Cattlemen's Association, an unrestricted gift from Balchem Corporation and funding for E. Estrada-Cortés by CONACyT- México
Results demonstrate that provision of the methyl-donor choline to the preimplantation embryo can alter its developmental program to increase gestation length, birth weight, and weaning weight and cause postnatal changes in muscle DNA methylation including those associated with genes related to anabolic processes and cellular growth. The importance of the nutritional status of the embryo with respect to one-carbon metabolism for ensuring health and well-being after birth is emphasized by these observations.

\section{INTRODUCTION}

Developmental programming is the phenomenon whereby changes in the environment of the developing organism or of the gametes from which it is derived reprograms aspects of development to modify postnatal phenotype. The phenomenon has been considered as an adaptive strategy shaped by evolution that prepares the animal for postnatal life under anticipated environmental conditions. ${ }^{1,2}$ Consequences of developmental programming can be harmful when individuals acquire a phenotype that is mismatched with the postnatal environment. An example of such a mismatch has been described in the human, where the combination of undernutrition during prenatal life and adequate nutrition postnatally leads to increased risk for metabolic and cardiovascular diseases during adulthood. ${ }^{3}$

The preimplantation period is a time when the developmental program is most plastic. The first differentiation events occur during this period (formation of epiblast, hypoblast, and trophoblast followed by initiation of gastrulation several days later) and the developing embryo undergoes large-scale, genome-wide changes in DNA methylation, histone epigenetic marks, chromatin accessibility, and gene expression..$^{4-6}$ A wide range of alterations in the maternal environment during the preimplantation period can alter postnatal phenotype including low-protein nutrition, ${ }^{7,8}$ growth hormone, ${ }^{9}$ lipopolysaccharide, ${ }^{10}$ and seminal plasma. ${ }^{11,12}$ Among the maternally derived molecules that have been reported to act on the preimplantation embryo to program postnatal phenotype are colony stimulating factor $2^{13,14}$ and dickkopf-related protein $1 .^{15}$

The mechanisms responsible for most examples of developmental programming have not been delineated. Changes in DNA methylation or histone modifications caused by environmental stimuli are often put forward as mechanisms for developmental programming. Not only do such changes alter capacity of cells for expression of specific genes but these epigenetic alterations can persist for long periods of time. Alterations in DNA methylation in whole blood were found in human individuals 60 years after they experienced the Dutch Hunger Winter of 1944 while fetuses. ${ }^{16}$ Several histone modifications near IGF1 caused by intrauterine growth retardation in rats were observed in the postnatal period. ${ }^{17}$

The potential role of DNA methylation in developmental programming implies that modification of one-carbon metabolism for the developing embryo or fetus could change postnatal phenotype by altering the pattern of DNA methylation. The importance of one-carbon metabolism during pregnancy for phenotype of the fetus and postnatal animal has been demonstrated several times at various periods of pregnancy ${ }^{18-20}$ Studies have also demonstrated the importance of methyl donors during a broad window of time encompassing the period before ovulation through the time of preimplantation development or later. ${ }^{21-23}$ Availability of methyl groups to the preimplantation embryo have been shown to change its capacity for development to the blastocyst stage and DNA methylation. ${ }^{24-28}$ No study, however, has focused specifically on the impact of methyl donor availability during preimplantation embryonic development on phenotype of the resultant offspring.

Choline is one component of one-carbon metabolism that has the potential to function as a developmental programming agent in the preimplantation period. Choline is a quarternary amine with three methyl groups that is a precursor of phosphatidylcholine and acetylcholine (via acetylation in nerve terminals) and which acts as a methyl donor through formation of methionine and Sadenosylmethionine. Prenatal intake of choline is important for brain development and postnatal central nervous function ${ }^{29,30}$ but its action to program other postnatal functions is unknown. Choline was one of the most abundant identified components of the metabolome in uterine fluid of cattle. ${ }^{31}$ Moreover, administration of choline altered gene expression and DNA methylation in cultured blastocysts. ${ }^{27}$

In the present study, the bovine embryo produced in vitro and cultured in a choline-free medium was used as a model to test the hypothesis that administration of choline during the period from the zygote through blastocyst formation would alter competence of the embryo to establish and maintain pregnancy after embryo transfer and postnatal growth of the resultant calf. It was also tested whether changes in postnatal body size are associated with alterations in DNA methylation at specific loci as 
identified by reduced representation bisulfite sequencing (RRBS). Results show for the first time how addition of a methyl donor to the environment of the preimplantation embryo can program the resultant animal for increased growth through a mechanism associated with changes in muscle DNA methylation. Paradoxically, the most common change in methylation status caused by choline was hypomethylation.

\section{2 | METHODS}

\section{1 | Animal care}

All procedures involving animals were approved by the Animal Care and Use Committee of the University of Florida and were performed in accordance with the relevant guidelines and regulations.

\subsection{Experimental design}

Embryos were produced in vitro using oocytes obtained by ultrasound-guided transvaginal ovum pick-up (OPU) from 18 Brahman cows (at least 70 days postpartum and with a suckling calf) and frozen-thawed semen from six Brahman bulls ( $n=1 \mathrm{X}$-sorted and $n=5$ conventional sperm). A donor was used to collect oocytes on $1(n=6), 2(n=10)$, or 3 ( $n=2)$ separate occasions. For each embryo production session $(n=4)$, all presumptive zygotes produced by a specific mating (bull and dam combination) were either randomly assigned to one treatment (if number of oocytes was $<24$ ) or randomly split into two with half assigned to control and half assigned to choline treatment. Control embryos were placed in a culture drop containing $0.0 \mathrm{mM}$ choline chloride (21 donor sessions; $n=332$ oocytes) and choline-treated embryos were placed in a culture drops containing $1.8 \mathrm{mM}$ choline chloride (25 donor sessions, $n=387$ oocytes). An additional $1.8 \mathrm{mM}$ sodium chloride was added to the control treatment to make the culture medium isotonic to the choline treatment. Embryos were exposed to treatment during the complete culture period.

Blastocysts were harvested at day 7 after fertilization and transferred fresh to one of 100 recipient cows (57 control- and 43 choline-treated embryos). The resultant calves were weighed at birth ( $n=11$ bulls and 13 heifers for control and $n=6$ bulls and 11 heifers for choline) and at weaning at $\sim 205$ days of age (average $=217$ days; range 177-250 days) ( $n=10$ bulls and 13 heifers for control and $3=$ bulls and 11 heifers for choline). A biopsy of Longissimus dorsi muscle was collected at 4 months of age (average $=129$ days; range 102-138 days) for analysis of DNA methylation from a subset of calves from control $(n=5$ females and $n=5$ bulls) and choline treatments ( $n=7$ females and $n=3$ males). Donors and recipients were kept in bahiagrass (Paspalum notatu) pastures during the experiment with free access to a complete mineral supplement (Lakeland Animal Nutrition, Lakeland, FL, USA).

\subsection{Production of embryos}

Embryos were produced in vitro using oocytes obtained by OPU performed without any hormonal treatments to synchronize follicular growth. Oocyte recovery was performed as described. ${ }^{14}$ The cumulus-oocyte complexes (COC) collected from each individual donor (6 to $23 \mathrm{COC}$ per donor; average $=15.6)$ were placed in a $1.5 \mathrm{ml}$ tube with maturation medium (Boviteq, Madison, WI, USA). The COC were matured in one (if the number was $\leq 30$ ) or two tubes (when number of COC > 30). Maturation was carried out for $22-24 \mathrm{~h}$ at $38.5^{\circ} \mathrm{C}$. The COC were washed three times in warmed HEPES-buffered Tyrode's albumin-lactate-pyruvate (HEPES-TALP) and once in drops of in vitro fertilization Tyrode's albumin-lactatepyruvate (IVF-TALP) pre-equilibrated at $38.5^{\circ} \mathrm{C}$ under $5 \%(\mathrm{v} / \mathrm{v}) \mathrm{CO}_{2}$. All matured $\mathrm{COC}$ from a single donor were placed in pre-equilibrated $60 \mu$ d drops of IVF-TALP covered with mineral oil (Minitube, Verona, WI, USA). Insemination was performed using frozen-thawed sperm from a single bull that was purified using PureSperm 40/80 gradient (Nidacon International AB, Mölndal, Sweden). A total of $20 \mu \mathrm{l}$ purified spermatozoa and $3.5 \mu \mathrm{l}$ of a solution of $0.5 \mathrm{mM}$ penicillamine, $0.25 \mathrm{mM}$ hypotaurine, and $25 \mu \mathrm{M}$ epinephrine were added to each drop. The final concentration of sperm in the drop was $1 \times 10^{6} \%$ $\mathrm{ml}$. Fertilization proceeded for $15-16 \mathrm{~h}$ at $38.5^{\circ} \mathrm{C}$ and $5 \%$ (v/v) $\mathrm{CO}_{2}$ in a humidified atmosphere. Cumulus cells were removed by vortexing presumptive zygotes (i.e., oocytes exposed to sperm) for $5 \mathrm{~min}$ in a tube containing $1000 \mathrm{IU} / \mathrm{ml}$ hyaluronidase and approximately $50 \mu \mathrm{l}$ HEPES-TALP.

Presumptive zygotes from each mating were cultured together and separately from those of other zygotes. The zygotes were washed three times in HEPES-TALP and then placed in $50 \mu \mathrm{l}$ drops of a choline-free medium called $\mathrm{BBH} 7$ (Cooley Biotech, Gainesville, Florida, $\mathrm{USA}^{32}$ ). Culture was performed in a benchtop incubator (Minc Incubator, Cook Medical, Bloomington, IN, USA) at $38.5^{\circ} \mathrm{C}$ in a humidified atmosphere of $5 \%(\mathrm{v} / \mathrm{v}) \mathrm{O}_{2}$ and $5 \%(\mathrm{v} / \mathrm{v}) \mathrm{CO}_{2}$ with the balance $\mathrm{N}_{2}$ supplied as premixed gas. For treatment preparations, a frozen aliquot of a control (1.8 M sodium chloride) or choline treatment (1.8 M choline chloride) was diluted 1:100 in BBH7 culture medium, and then diluted 1:10 by adding $5 \mu \mathrm{l}$ of control or choline treatment to a $45 \mu \mathrm{l}$ drop of culture medium. The final concentration in the drop was an 
additional $1.8 \mathrm{mM}$ sodium chloride for control and $1.8 \mathrm{mM}$ choline chloride for choline treatment.

The percent of presumptive zygotes (i.e., oocytes exposed to sperm) that cleaved was evaluated at day 3 after fertilization and the percent of presumptive zygotes and cleaved embryos becoming blastocysts was evaluated at day 7 after fertilization. Blastocysts with a grade 1 or 2 quality score were loaded individually into $0.25 \mathrm{ml}$ French straws with holding medium [HEPES-TALP $+10 \%$ (v/v) fetal bovine serum $+50 \mu \mathrm{M}$ dithithreitol]. Loaded straws were placed into a portable incubator (Micro Q Technologies, Scottsdale, Arizona, USA) at $38.5^{\circ} \mathrm{C}$ and transported to the farm for transfer into recipients.

\subsection{Embryo transfer}

Recipients were suckled crossbred cows containing various proportions of Angus and Brahman genetics and were at least 70 days postpartum. Ovulation was synchronized by injection, im, of $100 \mu \mathrm{g}$ gonadotropin releasing hormone (GnRH; Cystorelin, Boehringer Ingelheim, Duluth, GA, USA) and insertion of an intravaginal progesteronereleasing device (CIDR Zoetis, Parsippany-Troy Hills, NJ, USA) at day 0, removal of the CIDR and injection, im, of $25 \mathrm{mg}$ of prostaglandin F-2 $\alpha$ (Lutalyse, Zoetis) on day 7, and injection of $100 \mu \mathrm{g} \mathrm{GnRH}$ (Cystorelin, Boehringer Ingelheim) on day 9. The day of the last GnRH injection was considered as day 0 of the estrous cycle and embryo transfer was performed 7 days later for cows that had a functional corpus luteum based on transrectal ultrasonography of the ovaries. Each recipient meeting this criterion received a single blastocyst transferred into the uterine horn ipsilateral to the corpus luteum. Embryo transfer was preceded by induction of regional anesthesia induced by caudal epidural injection of $5 \mathrm{ml} 2 \%(\mathrm{w} / \mathrm{v}$ ) lidocaine hydrochloride (Aspen Veterinary Resources). A total of 57 control and 43 choline-treated embryos were transferred. Pregnancy diagnosis was performed at day 28 after embryo transfer by transrectal ultrasonography using an Ibex Pro ultrasound (E. I. Medical Imaging, Loveland, CO, USA). A cow was determined as pregnant when an embryonic vesicle and a viable embryo with heartbeat was detected.

\subsection{Collection of calf data}

Calves suckled their dams until weaning at about 205 days of age (range, 154-271 days) and were not creepfed. Body weights were collected within $24 \mathrm{~h}$ of birth and at weaning using an electronic True-Test scale (Wellington, Auckland, New Zealand). Hip height was also measured at weaning using a hip stick and while the legs were set squarely and head in a normal position. Daily growth rate was calculated from birth to weaning. Adjusted 205-day weaning weight was calculated using the formula [(weaning weight - birth weight)/days of age at weaning] $\times 205+$ birth weight (http://guidelines.beefimprovement.org/index.php/ Weaning_Weight). Males were not castrated during the experiment.

\section{6 | Statistical analysis of embryo, recipient, and calf data}

Statistical Analysis System version 9.4 (SAS Institute, Cary, NC, USA) was used for analyses. Data were initially analyzed using effects of treatment, replicate, mating and, for data collected after calving, sex and the sex by treatment interaction (i.e., sex $\times$ treatment). Data on birth weight were analyzed with and without gestation length as a covariate. Age at weaning was included as a covariate for traits measured at weaning. Non-significant effects explaining little variation were removed from the final model.

Binary response variables were analyzed by logistic regression models fitted to a binomial distribution using the GLIMMIX procedure. The final statistical model for percent of presumptive zygotes that cleaved after fertilization and presumptive zygotes and cleaved embryos becoming blastocysts included effects of treatment and replicate. The final model for data on cows pregnant at day 28 , cows that calved, and pregnancy loss between day 28 of gestation and calving date included effects of treatment; effects of replicate and mating were removed from the final model because they were not significant.

Variables with a continuous distribution were analyzed by analysis of variance using the GLM procedure of SAS. The final statistical model for gestation length included treatment and mating effects. The final model for weaning weight included effects of treatment, sex, and sex $\times$ treatment. The final model for birth weight, hip height at weaning, weight to hip height ratio at weaning, average daily gain from birth to weaning and 205-day adjusted body weight at weaning included treatment, sex, treatment $\times$ sex and mating.

\section{7 | Muscle samples and DNA extraction}

A subgroup of resultant calves from control (females $n=5$ and males $n=5$ ) and choline treatments (females $n=7$ 
and males $n=3$ ) were subjected to a biopsy in the $L$ dorsi muscle at 4 months of age. The incision region was clipped and cleaned with a germicidal scrub containing povidoneiodine followed by a $70 \%$ isopropyl alcohol rinse. Calves received subcutaneous and intramuscular injections of a total of $10 \mathrm{ml} \mathrm{2 \%} \mathrm{(w/v)} \mathrm{lidocaine} \mathrm{hydrochloride} \mathrm{(Aspen}$ Veterinary Resources) to anesthetize the site of incision. An incision of $\sim 0.5 \mathrm{cc}$ was made with a sterile scalpel blade to allow passage of the biopsy instrument (SuperCore Biopsy Instrument 14 ga $\times 9 \mathrm{~cm}$, Aragon Medical Devices, Frisco, TX, USA). After obtaining the biopsy, the wound was closed using glue and AluShield (aerosol bandage) was sprayed on the incision site. A new sterile biopsy needle was used for each individual animal. Muscle samples ( $20 \mathrm{mg}$ ) were rinsed three times in Dulbecco's phosphate buffered saline, placed in $2 \mathrm{ml}$ DNase free tubes (Costar, Corning, NY, USA) and frozen in liquid nitrogen. Samples were maintained at $-80^{\circ} \mathrm{C}$ until subsequent analysis.

DNA extraction was performed using the PureLink Genomic DNA Mini Kit (Thermo Fisher Scientific, Waltham, MA, USA) as described in the kit. In preparation for DNA extraction, individual samples were ground with a pestle motor mixer (Fisher Scientific, Lenexa, KS, USA) in a $2 \mathrm{ml}$ DNase free screw cap tube (Fisher), and then homogenized with sterile $2 \mathrm{~mm}$ zirconium beads (Fisher) and $180 \mu \mathrm{ldi}$ gestion buffer from the PureLink kit in a Precellys 24 homogenizer (Bertin Technologies, Montigny-leBretonneux, France) programmed for 12 cycles of $10 \mathrm{~s}$ each at $1000 \mathrm{rpm}$. Samples were centrifuged for $15 \mathrm{~min}$ at $7.5 \mathrm{~g}$ (Sorvall Legend Micro 21, Thermo Fisher Scientific) and supernatant was transferred to a new $2 \mathrm{ml}$ DNase tube (Costar, Corning) for extraction.

\section{8 | Library construction for reduced- representation bisulfite sequencing}

Procedures were performed by Novogene Co. Ltd. (Chaoyang, Bejing, China). DNA samples were analyzed by agarose electrophoresis to evaluate degradation and RNA contamination and by Qubit Fluorometric Quantification 2.0 (Thermo Fisher Scientific) to determine DNA concentration. For library construction, $\lambda$ DNA was added as a negative control to individual DNA samples $(1.5 \mu \mathrm{g} / \mathrm{ml}$ per sample), which were digested using the methylation-insensitive restriction enzyme MspI. DNA fragments were repaired, dA-tailed, and ligated to sequencing adaptors in which all cytosines are methylated. DNA fragments were size selected with insertion lengths ranging from 40 to 220 bp by gel cutting ${ }^{33}$ (Meissner, 2008). Size-selected DNA fragments were bisulfite treated with EZ DNA Methylation Gold Kit (Zymo Research, Irvine, CA, USA) to convert unmethylated cytosines to uracil The final DNA library was obtained by PCR amplification.

After library construction, initial quantification was performed with Qubit 2.0 and the library was diluted to $1 \mathrm{ng} / \mathrm{L}$. Insertion size of the library was determined using the Agilent 2100 Bioanalyzer Instrument (Santa Clara, CA, USA) and concentration of the library quantified again by quantitative -PCR (library effective concentration $>2 \mathrm{nM}$ ). After quality control, sequencing was performed on the Illumina HiSeq/NovaSeq platform (San Diego, CA, USA).

\subsection{Quality checking and read alignment}

The original images obtained from the sequencing platform were saved in FASTQ format and subjected to quality control analysis by calculating Phred scores with the Illumina CASAVA v1.8 software. Low-quality reads and contaminated adapter sequences were filtered using the Trimmomatic tool. The minimum read length to be kept was $36 \mathrm{nt}$, and unpaired reads after trimming were discarded. The clean reads were aligned to the Bos taurus reference genome (bosTau 9) downloaded from the University of California, Santa Cruz (UCSC) database using the Bismark Bisulifte Read Marker v 0.22.3. ${ }^{34}$

The bisulfite conversion rate ranged from $99.077 \%$ to $99.268 \%$, and the proportion of bases with at least Phred quality score 20 was $97.65 \%$. The number of total reads was from 22.9 to $40.3 \mathrm{Mb}$, mapped reads ranged from 8.2 to $11.8 \mathrm{Mb}$, mapping rate ranged from $21.0 \%$ to $35.75 \%$, and MspI digestion efficiency ranged from $86.68 \%$ to $96.36 \%$. The base number mapped onto the genome in C and CG context $(\mathrm{Mb})$ ranged from 33.2 to 65.9 and 6.9 to 9.7 respectively.

\subsection{0 | Quantification and determination of differentially methylated cytosines (DMC)}

All covered cytosines were used for calculation of global CpG methylation amount in Bismark using the following formula: percent global methylation $=$ number of methylated cytosines/total number of cytosines $\times 100$. The BAM files from Bismark were analyzed using the Bioconductor package methylKit ${ }^{35}$ for the $\mathrm{R}$ software. First, read coverages lower than 10 counts or higher than the 99.9th percentile were filtered out to discard low-coverage and clonal reads. Next, the distributions of the read coverage were normalized between samples, and samples were merged to retain reads with CpGs 
covered in at least five samples (two for males, three for females).

The number of CpGs retained after quality control was 8149 . Identification of DMC was performed by logistic regression analysis fit to a binomial distribution. All samples from both females and males were used. In the statistical model, treatment and sex of calf were included as class effects and age of calf was included as a covariate. $p$-values were adjusted for multiple testing and $q$-values were obtained by using the sliding linear model method. ${ }^{36}$ Those DMC where the $q$ value was $<0.05$ were considered significant.

\subsection{1 | Annotation and functional analysis of DMC}

Annotation was performed with the Bioconductor/R package Genomation. ${ }^{35}$ The BED files of CpG islands and RefSeq database for the bosTau 9 assembly were downloaded from the UCSC table browser (https://genome.ucsc.edu/cgi-bin/hgTables). All DMC were annotated with nearest (no specific cut off) transcriptional start site (TSS). Promoters and CpG shore were defined as \pm 1000 and $\pm 2000 \mathrm{bp}$ of the TSS and CpG islands respectively.

Each DMC was associated with the gene within which it was located or to which it was most closely mapped. A total of 277 genes were so identified. Functional analysis of these genes was performed using Ingenuity Pathway Analysis (IPA, Qiagen, Valencia, CA, USA). Of the 277 genes, 193 were mapped by IPA. The core analysis function of IPA was used to identify the top canonical pathways, molecular and cellular function categories, and physiological system development and function categories that were influenced by choline treatment.

\section{3 | RESULTS}

\section{1 | Embryo development and pregnancy outcomes}

Results for in vitro embryo development are shown in Table 1 . The percent of oocytes that cleaved after fertilization was slightly higher for choline than control

\begin{tabular}{|c|c|c|c|}
\hline \multirow[b]{2}{*}{ Trait } & \multicolumn{2}{|c|}{ Treatment } & \multirow{2}{*}{$\begin{array}{l}p \text {-value, } \\
\text { treatmen }\end{array}$} \\
\hline & Control & Choline & \\
\hline $\begin{array}{l}\text { Number of donor sessions (number of } \\
\text { oocytes) }\end{array}$ & $25(387)$ & $21(332)$ & - \\
\hline $\begin{array}{l}\text { Presumptive zygotes that cleaved after } \\
\text { fertilization, } \%\end{array}$ & $80.6 \pm 2.3$ & $86.2 \pm 1.9$ & .0496 \\
\hline $\begin{array}{l}\text { Cleaved embryos becoming } \\
\text { blastocysts, } \%\end{array}$ & $16.3 \pm 2.5$ & $15.9 \pm 2.2$ & .9053 \\
\hline $\begin{array}{l}\text { Presumptive zygotes becoming } \\
\text { blastocysts, } \%\end{array}$ & $12.7 \pm 2.0$ & $13.7 \pm 2.0$ & .6602 \\
\hline
\end{tabular}

TA B L E 1 Effect of choline treatment during culture on embryonic development $^{\mathrm{a}}$

${ }^{\mathrm{a}}$ Data on cleavage and development are presented as least-squares means $\pm \mathrm{SEM}$.

T A B LE 2 Effect of choline treatment during culture on pregnancy outcomes after embryo transfer ${ }^{\mathrm{a}}$

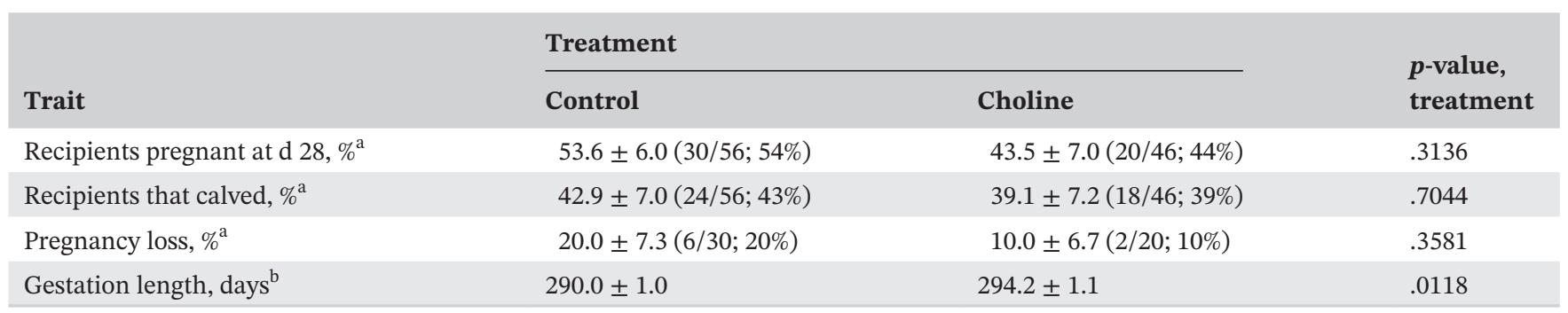

${ }^{\mathrm{a}}$ Data are least-squares means \pm SEM and, in parentheses, the fraction and percent of cows.

${ }^{b}$ Data are least-squares means \pm SEM. One animal in the choline group with premature calving (277 days) was removed from the data set before analysis. There was no effect of sex or sex $\times$ treatment. 
( $p=.0496)$ but there was no effect of choline on the percent of cleaved embryos or presumptive zygotes becoming blastocysts.

Results for pregnancy outcomes after embryo transfer are summarized in Table 2. There were no effects of treatment on the percent of cows pregnant at day 28 , cows that calved, and pregnancy loss between day 28 of gestation and calving date. However, there was a treatment effect on the gestation length of recipients. After excluding one cow with premature birth (277 days), gestation length was longer $(p=.0118)$ for recipients which received a choline-treated embryo than for these receiving a control-treated embryo. There was no effect of $\operatorname{sex}(p=.9208)$ or interaction of treatment and sex ( $p=.5447)$ on gestation length. The least-squares means for gestation length were $289.6 \pm 1.4$ days for controlfemale, $294.3 \pm 1.4$ days for choline-female, $290.6 \pm 1.6$ for control-male, and $293.7 \pm 1.9$ days for choline-male respectively.

\section{2 | Postnatal characteristics of body size and growth}

Results are shown in Table 3 . Birth weight was greater ( $p=.0081$ ) for the choline group than the control group. This was true for both female and male calves as indicated by the lack of an interaction between sex and treatment ( $p=$.9603). When data were adjusted for differences in gestation length, there were still differences in birth weight between treatments $(p=.0857)$ but differences were of smaller magnitude. Thus, some, but not all, of the treatment effect on birth weight was due to longer gestation lengths.

None of the calves were abnormally large at birth; birth weights were within the range of birth weights for other Brahman calves at the farm born as a result of artificial insemination. A total of four calves died between birth and weaning. Three of these calves died in the same week at 1 to 3 days of age as a result of hypothermia because of cold weather. The fourth died at 4 days of age for unknown reasons.

Weaning weight tended $(p=.085)$ to be greater for calves derived from choline-treated embryos. This difference was significant ( $p=.0477)$ when weaning weight was adjusted for a standard 205-day of age weaning weight. There was no effect of treatment on hip height at weaning but the ratio of weight to hip height was greater ( $p=.0378$ ) for the choline group. Thus, the greater weight of the choline calves does not represent an increase in stature but rather development of body mass per unit height. As for birth weight, there were no effects of sex or sex $\times$ treatment affecting traits measured at weaning. There was no significant effect of treatment on average daily gain from birth to weaning.

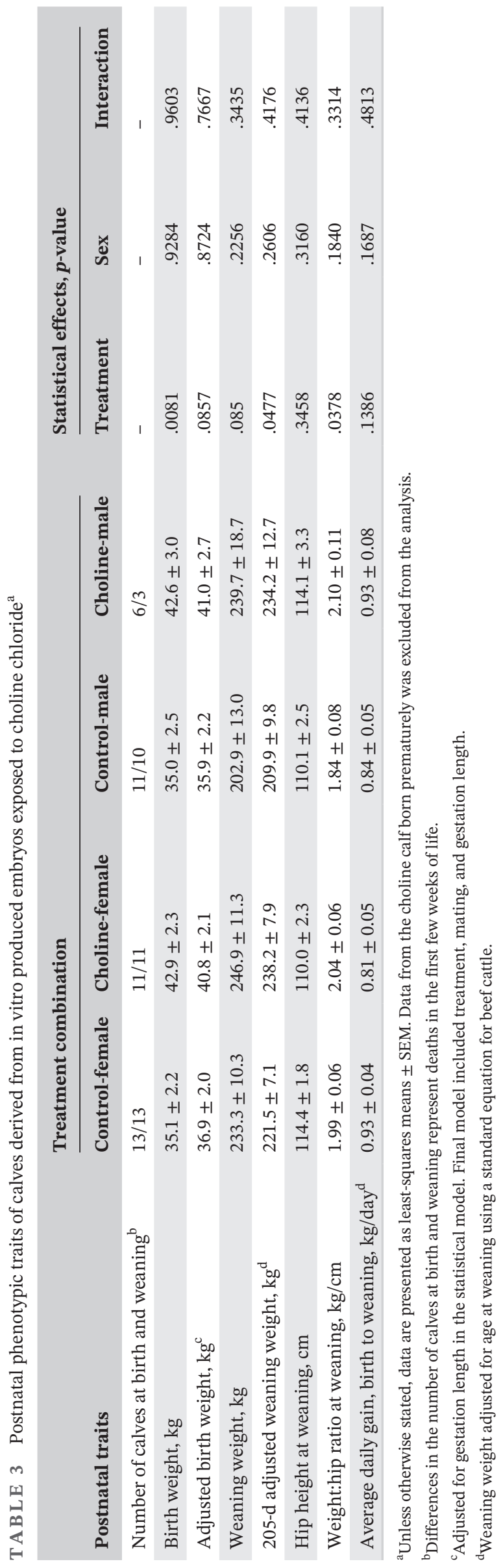




\subsection{DNA methylation profile in muscle of calves}

The total number of $\mathrm{CpG}$ analyzed were 8149 (Supporting File S1, Table S1). Of these, there were 670 that were differentially methylated due to treatment after adjustment for multiple testing, with $239 \mathrm{CpG}$ hypermethylated and 431 hypomethylated in choline calves. The DMC were primarily located in a few chromosomes, with $30 \%$ located on BTA 27, $7.2 \%$ on BTA 13 and $5.4 \%$ on BTA 29 (Figure 1). Over half the DMC (51.8\%) were associated with protein coding genes, $26.9 \%$ were associated with ribosomal RNA, 19.1\% with non-coding RNA and the remainder with pseudogenes (1.8\%) and small nuclear ribonucleoproteins (0.4\%). There were $342 \mathrm{DMC}$ in $\mathrm{CpG}$ and 146 in $\mathrm{CpG}$ shores.

Of the $670 \mathrm{DMC}, 392$ were in either the promoter, exonic or intronic regions of genes, representing 196 genes. A total of $155 \mathrm{DMC}$ were in promoters representing 53 genes. A large number of DMC were associated with a few genes (Table 4). One region on BTA 27 accounted for $177 \mathrm{DMC}$, that is, $26.4 \%$ of all DMC. There were two genes in this region: LOC11244653 (5.8 S ribosomal RNA), associated with 148 DMC and RN18S1, associated with 29 DMC (Figure 2). Together, the top 10 most differentially methylated genes accounted for 294 DMC (43.9\% of the total).

Functional annotation of genes associated with DMC was performed by IPA. A total of 191 of the 277 genes included in the list for IPA were mapped. As shown in Figure 3, the top 5 significant physiological functions associated with DMC were tissue development, organismal development, embryonic development, organ development and auditory and vestibular system development and function. The top 5 significant molecular and cellular functions were cellular development, cellular growth and proliferation, cellular movement, cellular death and survival, and lipid metabolism.

There was a total of 87 canonical pathways in which genes with $\mathrm{DMC}$ were overrepresented at $p<.05$. Of these, six remained significant after Bonferonni-Hochberg correction for multiple testing was applied: AMPK signaling (11 genes), ceramide signaling (7 genes), dilated cardiomyopathy signaling pathway ( 7 genes), mTOR signaling (8 genes), integrin signaling (8 genes), and BEX2 signaling pathway (5 genes) (Supporting File S1, Table S2). Illustration of genes in the mTOR signaling pathway, which plays an important role in muscle, is depicted in Figure 4.

\section{DISCUSSION}

Here, we demonstrate that provision of methyl groups to the preimplantation embryo can alter its developmental

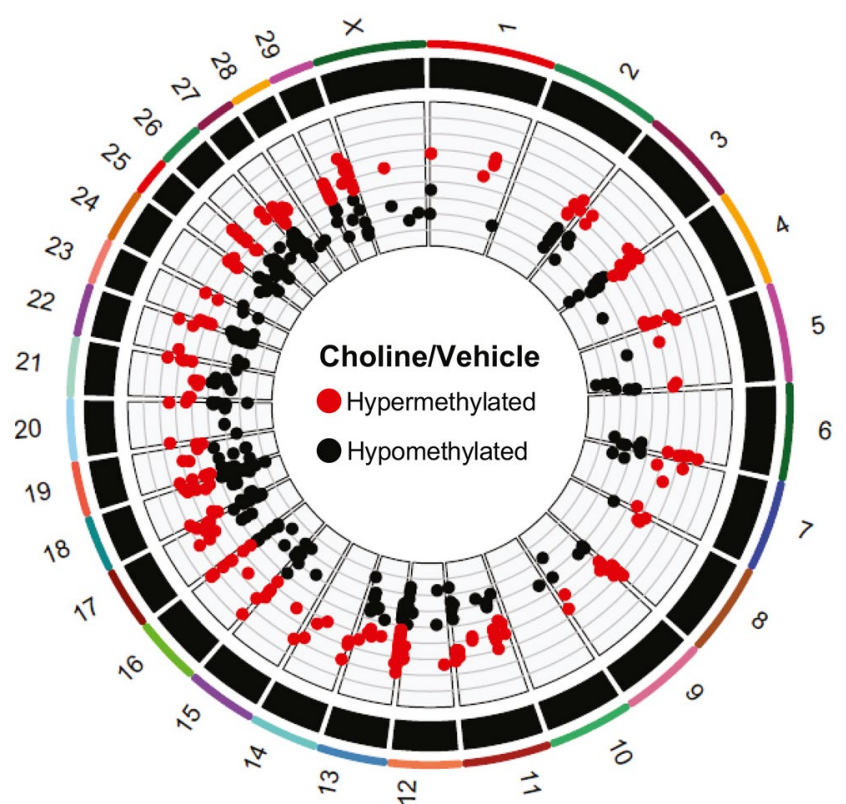

F I G U R E 1 Circos plot illustration of chromosomal distribution and degree of change in DNA methylation for specific differentially methylated cytosines in Longissimus dorsi of 4-month old calves as modified by exposure to choline during preimplantation development. Red dots represent cytosines that were hypermethylated due to choline $(n=239)$ and black dots represent cytosines that were hypomethylated due to choline $(n=431)$. The scale is such that each line represents a difference in methylation of $10 \%$

program in a way that, in cattle, increases gestation length, birth weight, weaning weight and causes postnatal changes in DNA methylation patterns in muscle. This is the first report that provision of a one-carbon cycle substrate specifically in the preimplantation period can program events later in the postnatal period. This is also the first report that choline by itself causes programming of postnatal traits other than brain function. ${ }^{29,30}$ These results provide further evidence of the plasticity of the developmental program during preimplantation development and are indicative that the nutritional status of the embryo in vitro and in vivo with respect to one-carbon metabolism can be important for ensuring health and well-being after birth.

Production of embryos in vitro is associated with altered phenotypes after birth in several species. ${ }^{37,38}$ The environment of the oocyte and embryo subjected to in vitro maturation, fertilization, and development differs in many respects from its counterpart in the female reproductive tract. One notable characteristic of culture media used for in vitro production of embryos is the paucity of methyl donors. Vitamins are not typically included in such culture systems and usually the only methyl donor present is the amino acid methionine. The present data are indicative that absence of an adequate supply of methyl donors in culture medium may result in the one-carbon nutrition of 
T A B L E 4 Properties of the 10-most differentially methylated genes in Longissimus dorsi

\begin{tabular}{|c|c|c|c|c|c|c|}
\hline \multirow[b]{2}{*}{ Gene } & \multirow[b]{2}{*}{ Name } & \multirow[b]{2}{*}{ Chromosome } & \multicolumn{4}{|c|}{$\begin{array}{l}\text { Number of differentially methylated } \\
\text { cytosines }^{\text {a }}\end{array}$} \\
\hline & & & Total $^{\text {b }}$ & Promoter & Exon & Intron \\
\hline LOC112444653 & 5.8S ribosomal RNA & 27 & 148 & 71 & 8 & 0 \\
\hline LOC616519 & Noncoding RNA & 13 & 33 & 0 & 0 & 0 \\
\hline MIR2887-2 & MicroRNA 2887-2 & 27 & 16 & 2 & 0 & 0 \\
\hline OR4C1F & $\begin{array}{l}\text { Olfactory receptor family } 4 \text { subfamily } \mathrm{C} \\
\text { member } 1 \mathrm{~F}\end{array}$ & 19 & 12 & 0 & 0 & 0 \\
\hline LOC112442278 & Basic proline-rich protein-like & 2 & 11 & 0 & 3 & 6 \\
\hline LOC101906171 & Liprin-alpha-1-like & 23 & 8 & 0 & 1 & 7 \\
\hline
\end{tabular}

${ }^{\mathrm{a}}$ The total number of differentially methylated cytosines associated with each gene is less than the sum of differentially methylated cytosines in the promoter, exons, and intronic regions because some DMC were designated in more than one region.

${ }^{\mathrm{b}}$ Included $\mathrm{CpG}$ islands and $\mathrm{CpG}$ shores.

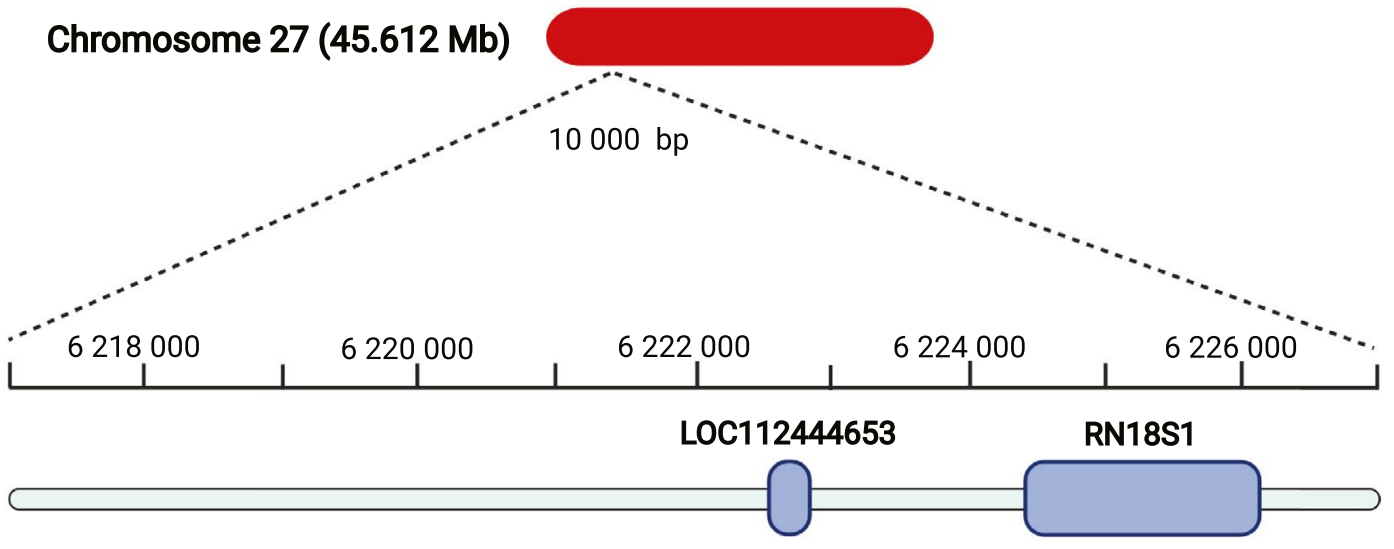

$$
\begin{aligned}
& \text { Differentially } \\
& \text { methylated cytosines } \\
& \text { - Hypomethylated } \\
& \text { - Hypermethylated }
\end{aligned}
$$

\section{- Hypermethylated}

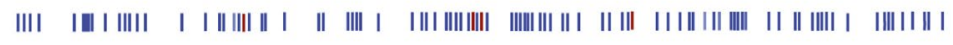

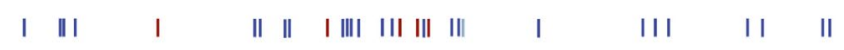

F I G U RE 2 Illustration of the DNA methylation profile in a segment of BTA 27 between 6219000 and 6227000 bp. This segment includes 139 hypomethylated and 9 hypermethylated cytosines associated with the 5.8S ribosomal RNA gene LOC112444653 and 29 hypomethylated cytosines associated with the 18S ribosomal RNA gene RN18S1. Blue lines represent cytosines that were hypomethylated in choline calves and red lines represent hypermethylated cytosines in choline calves. Alignment was performed by using the genome assembly Bos taurus ARS-UCD1.2

the embryo produced in vitro being inadequate for optimal development. It may also be that the reproductively-active female could also sometimes be deficient in methyl donor sources. Feeding rumen-protected methionine to cattle has been reported to increase amniotic vesicle volume and embryo diameter at day 33 of pregnancy ${ }^{39}$ while feeding both rumen-protected methionine and choline improved fertility. ${ }^{40}$ More work on impact of maternal methyl donor nutrition on fertility and postnatal outcomes of the offspring is warranted.

The mechanism by which choline acts during the preimplantation period to affect gestation length and postnatal body weight is not known but results are consistent with the hypothesis that changes in DNA methylation 


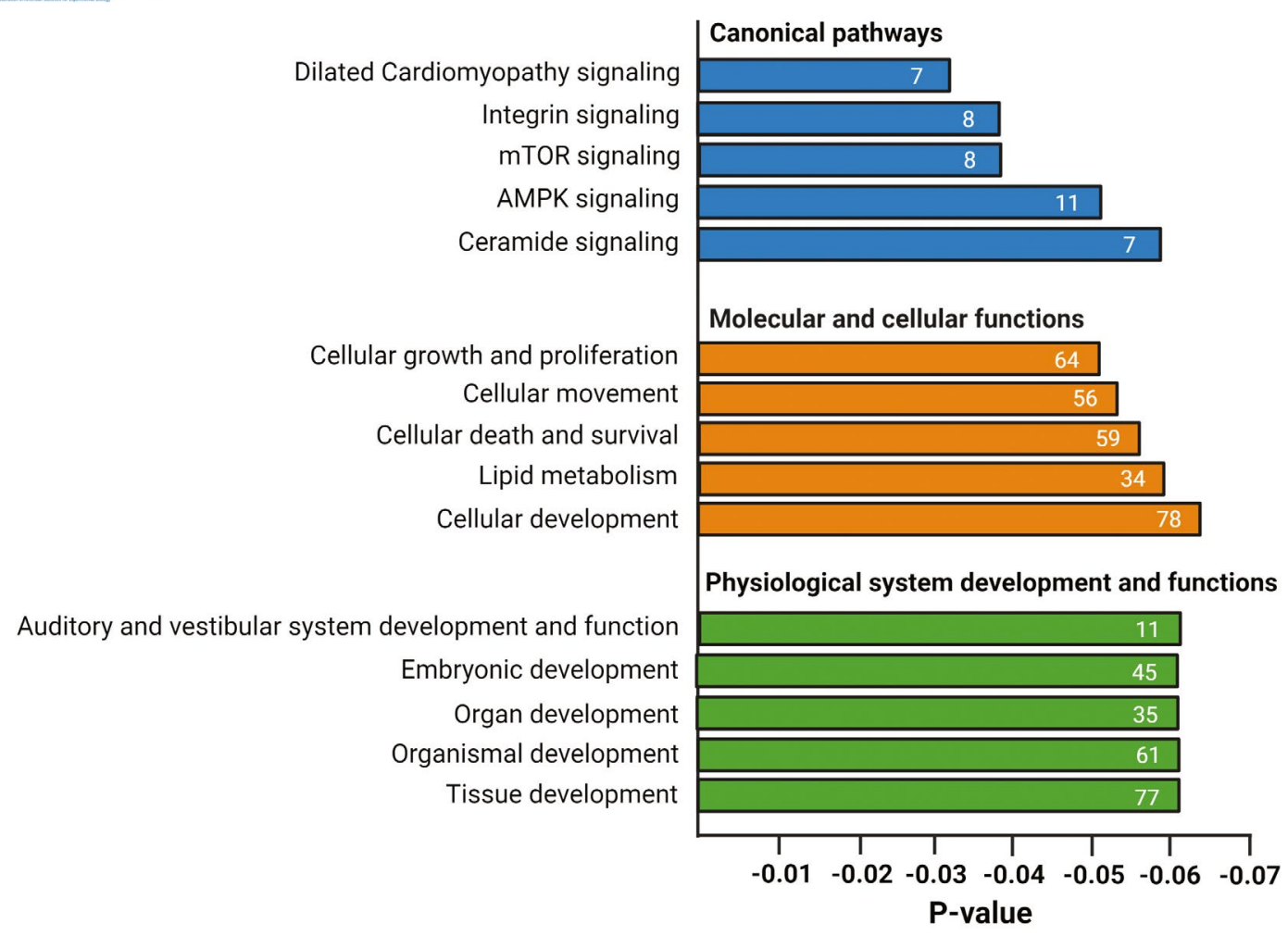

F I G U RE 3 Results of functional annotation for the differentially methylated cytosines influenced in choline calves. This figure illustrates the top 5 canonical pathways, cellular functions, and physiological functions. The number of molecules with significant CpG is indicated in each bar. Analysis was performed by Ingenuity Pathway Analysis

are involved. Two lines of evidence support this idea. First, choline treatment of the preimplantation embryo resulted in changes in specific $\mathrm{CpG}$ in the $L$ dorsi muscle of calves at 4 months of age. Indeed, $9 \%$ of $\mathrm{CpG}$ examined experienced differential methylation as a result of choline treatment. Secondly, many of the DMC were located in genomic regions potentially important for postnatal growth. The genomic regions with the most extensive alterations in DNA methylation were the ribosomal genes LOC112444653 (encoding for 5.8S RNA) and RN18S1 (encoding for 18S RNA). The predominant change in methylation for these genes due to choline was hypomethylation. Ribosomes are central to conversion of mRNA to protein ${ }^{41}$ and an increase in mRNA coding for ribosomal RNAs have been observed during hypertrophy of rat cardiomyocytes, ${ }^{42}$ plantaris muscle in rat and vastus lateralis in human. ${ }^{43}$ Reduction in methylation of genomic regions of ribosomal DNA is associated with increased biogenesis of ribosomal RNA. ${ }^{44}$ Furthermore, many of the genes associated with DMC are associated with growth or muscle function. There was an overrepresentation of genes associated with DMC in the mTOR anabolic pathway, which has stimulatory actions on ribosome biogenesis and growth of skeletal muscle. ${ }^{45}$ Many genes associated with DMC were categorized as being involved in cellular growth, organ development, organismal development, and tissue development. One gene, LOC10190671, associated with eight DMC, is analogous to liprin- $\alpha 1$ which is a component of the neuromuscular junction. ${ }^{46}$ Another, PLCG1, with 5 DMC, mediates cell-signaling events in smooth muscle. ${ }^{47}$

What is not known from the current experiment is whether the changes in DNA methylation observed in calves at 4 months of age were first induced in the preimplantation embryo and subsequently inherited or whether modifications of DNA methylation represent secondary actions resulting from earlier changes in embryonic function caused by choline. Choline can change global DNA methylation of the blastocyst-stage preimplantation embryo, as evaluated by labeling with antibody to 5 -methylcytosine ${ }^{27}$ but it is not known whether the same loci undergoing differential methylation in the blastocyst are those that were differentially methylated in the calf 13 months later. Some changes in methylation caused by choline during the preimplantation period may have been modified by 4 months after birth. Only $5 \%$ of changes in methylation of specific $\mathrm{CpG}$ associated with preterm birth in neonates were still differentially methylated when individuals were 18 years old. ${ }^{48}$ More research should be conducted to determine to what extent the potential epigenetic marks induced by choline in preimplantation embryos remain in resultant offspring after embryo transfer. 


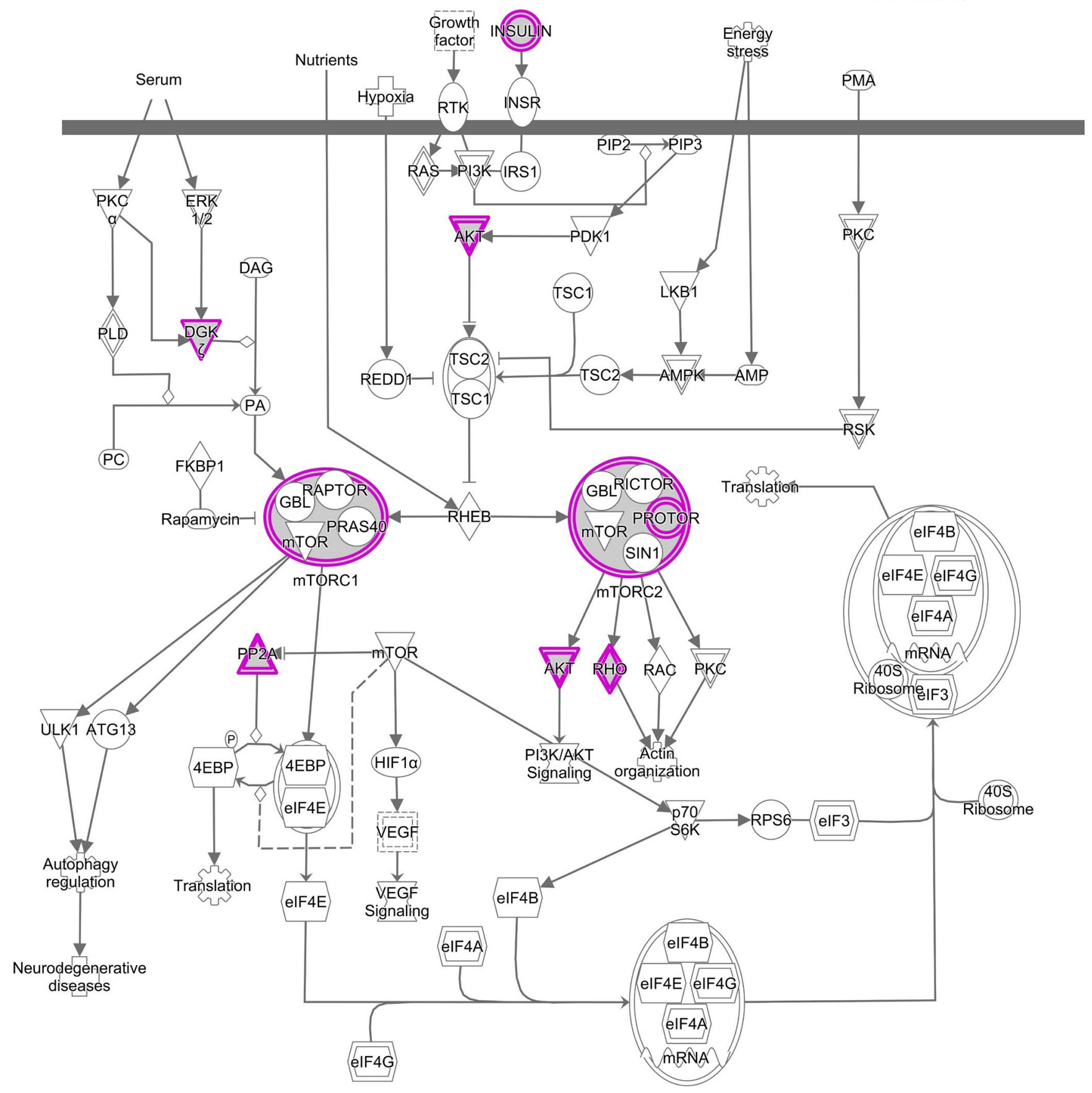

F I G U RE 4 Illustration of the mTOR pathway to show those genes associated with differentially methylated cytosines (outlined in purple). The figure was generated by Ingenuity Pathway Analysis.

Labeling for 5-methylcytosine in the blastocyst was increased by culture with choline ${ }^{27}$ but the predominant action of choline on the methylome of the calf was hypomethylation. This result was unexpected because choline is a methyl donor but, in fact, provision of methyl donors can result in DNA hypomethylation globally or at specific genomic regions. ${ }^{26,49,50}$ Choline deficiency during pregnancy in rats leads to global DNA hypermethylation in fetal liver while choline supplementation caused hypomethylation in brain. ${ }^{51}$ These actions were caused by regulation of Dnmt1 expression. Choline deficiency resulted in increased expression of Dnmt1 in liver and choline supplementation decreased expression of Dnmt1 in brain. ${ }^{51}$ Both changes in expression were associated with changes in methylation of Dnmt1. The technique used here to evaluate DNA methylation, RRBS, does not interrogate the entire genome and DNMT1 was not associated with one of the $8149 \mathrm{CpG}$ evaluated. Another gene involved in regulation of DNA methylation, EHMT1, ${ }^{52}$ contained an intronic $\mathrm{CpG}$ that was 
hypermethylated by choline treatment. Furthermore, its inhibition was associated with increased expression of genes involved in the phosphatidylinositol 3 kinase and mTOR pathways. ${ }^{53}$

One of the actions of choline during preimplantation development was to increase gestation length. It has been hypothesized that reduction in gestation length may represent a predictive adaptive response to adverse environments. ${ }^{54}$ Perhaps, such a phenomenon is occurring in the current case, if culture conditions for the embryo are viewed as an adverse environment and choline improves that environment. Gestation length is controlled by maturation of the hypothalamic-pituitary axis. ${ }^{55}$ Increased choline intake during the last trimester increased methylation of the promoter region of key genes in regulation of cortisol metabolism. ${ }^{56} \mathrm{~A}$ similar action of choline during the preimplantation period, if occurring, could delay onset of parturition and increase gestation length.

Increases in gestation length are associated with higher birth weight. ${ }^{57}$ While some of the effect of choline on birth weight is partially explained by the increase in gestation length, an effect of choline independent of gestation length was evidenced by differences in birth weight after adjustment for gestation length. In pigs, supplementation with a cocktail of methyl donors during the periconceptional period increased fetal weight at day 90 of age and this outcome was associated with an increased gene expression of $I G F 1$ in muscle tissue. ${ }^{23}$ It remains to be seen whether choline treatment in the preimplantation period programs the embryo to alter secretion of anabolic hormones or growth factors later in development.

One of the characteristics of developmental programming during the preimplantation period is that the consequences for postnatal function often differ for male and female offspring. ${ }^{38}$ In the present experiment, there were no significant interactions between choline treatment and sex. However, the number of observations was small, especially for males, and future experiments should re-evaluate the possibility of choline programming the male blastocyst differently than the female one.

In conclusion, provision of the methyl-donor choline to the preimplantation embryo can alter its developmental program to increase gestation length, birth weight, and weaning weight, and postnatal changes in DNA methylation patterns in muscle, especially for genes related to anabolic processes and cellular growth. The importance of the nutritional status of the embryo in vitro and in vivo with respect to one-carbon metabolism for ensuring health and well-being after birth is emphasized by these observations.

\section{ACKNOWLEDGMENTS}

The authors acknowledge Danny Driver, Michelle Driver, Bert Faircloth, and all personnel at the Beef Research Unit and Santa Fe River Ranch Unit of the University of Florida for assistance with the management of Brahman donors, recipients and calves. Thanks are also extended to Audy Spell and Joel Carter for assistance with embryo transfer.

\section{DISCLOSURES}

PJ Hansen and J Block are co-owners of Cooley Biotech LLC, the manufacturer of $\mathrm{BBH} 7$ culture medium. The other authors declare no conflicts of interest.

\section{AUTHOR CONTRIBUTIONS}

Eliab Estrada-Cortés and Peter J. Hansen designed the experiment, Eliab Estrada-Cortés, Maria B. Rabaglino, and Peter J. Hansen analyzed the data, Eliab Estrada-Cortés, William Ortiz, Jeremy Block, Owen Rae, Elizabeth A. Jannaman, Yao Xiao, and Peter J. Hansen performed the research, Eliab Estrada-Cortés, Maria B. Rabaglino, and Peter J. Hansen wrote initial drafts of the paper, and all authors contributed to the final paper.

\section{ORCID}

Eliab Estrada-Cortés (1) https://orcid.

org/0000-0003-0226-9794

William Ortiz (D) https://orcid.org/0000-0002-7335-3961

Maria B. Rabaglino (D) https://orcid.

org/0000-0002-0099-045X

Jeremy Block (i) https://orcid.org/0000-0002-6279-8543

Elizabeth A. Jannaman (1) https://orcid.

org/0000-0003-2461-6793

Yao Xiao (1) https://orcid.org/0000-0002-5153-6839

Peter J. Hansen (D) https://orcid.org/0000-0003-3061-9333

\section{REFERENCES}

1. Gluckman PD, Hanson MA, Beedle AS. Early life events and their consequences for later disease: a life history and evolutionary perspective. Am J Hum Biol. 2007;19:1-19. doi:10.1002/ ajhb. 20590

2. Lafuente E, Beldade P. Genomics of developmental plasticity in animals. Front Genet. 2019;10:720. doi:10.3389/ fgene.2019.00720

3. Barker DJ, Thornburg KL. Placental programming of chronic diseases, cancer and lifespan: a review. Placenta. 2013;34:841845. doi:10.1016/j.placenta.2013.07.063

4. Pfeffer PL. Building principles for constructing a mammalian blastocyst embryo. Biology. 2018;7:41. doi:10.3390/biology7030041

5. Eckersley-Maslin MA, Alda-Catalinas C, Reik W. Dynamics of the epigenetic landscape during the maternal-to-zygotic transition. Nat Rev Mol Cell Biol. 2018;19:436-450. doi:10.1038/s4158 0-018-0008-Z

6. Greenberg MVC, Bourc'his D. The diverse roles of DNA methylation in mammalian development and disease. Nature Rev Mol Cell Biol. 2019;20:590-607. doi:10.1038/s41580-019-0159-6 
7. Gould JM, Smith PJ, Airey CJ, et al. Mouse maternal protein restriction during preimplantation alone permanently alters brain neuron proportion and adult short-term memory. Proc Natl Acad Sci U S A. 2018;115:E7398-E7407. doi:10.1073/ pnas. 1721876115

8. Watkins AJ, Ursell E, Panton R, et al. Adaptive responses by mouse early embryos to maternal diet protect fetal growth but predispose to adult onset disease. Biol Reprod. 2008;78:299-306. doi:10.1095/biolreprod.107.064220

9. Koch JM, Wilmoth TA, Wilson ME. Periconceptional growth hormone treatment alters fetal growth and development in lambs. J Anim Sci. 2010;88:1619-1625. doi:10.2527/ jas.2009-2392

10. Williams CL, Teeling JL, Perry VH, Fleming TP. Mouse maternal systemic inflammation at the zygote stage causes blunted cytokine responsiveness in lipopolysaccharide-challenged adult offspring. BMC Biol. 2011;9:49. doi:10.1186/1741-7007-9-49

11. Bromfield JJ, Schjenken JE, Chin PY, Care AS, Jasper MJ, Robertson SA. Maternal tract factors contribute to paternal seminal fluid impact on metabolic phenotype in offspring. Proc Natl Acad Sci U S A. 2014;111:2200-2205. doi:10.1073/pnas.1305609111

12. Ortiz WG, Rizo JA, Carvalheira LR, et al. Effects of intrauterine infusion of seminal plasma at artificial insemination on fertility of lactating Holstein cows. J Dairy Sci. 2019;102:6587-6594. doi:10.3168/jds.2019-16251

13. Kannampuzha-Francis J, Denicol AC, Loureiro B, Kaniyamattam K, Ortega MS, Hansen PJ. Exposure to colony stimulating factor 2 during preimplantation development increases postnatal growth in cattle. Mol Reprod Develop. 2015;82:892-897. doi:10.1002/mrd.22533

14. Estrada-Cortés E, Jannaman EA, Block J, Amaral TF, Hansen PJ. Programming of postnatal phenotype caused by exposure of cultured embryos from Brahman cattle to colony stimulating factor 2 and serum. J Anim Sci. 2021;99:skab180. doi:10.1093/ jas/skab180

15. Tríbulo P, Bernal-Ballesteros BH, Ruiz A, et al. Consequences of exposure of embryos produced in vitro in a serum-containing medium to dickkopf-related protein 1 and colony stimulating factor 2 on blastocyst yield, pregnancy rate, and birth weight. $J$ Anim Sci. 2017;95:4407-4412. doi:10.2527/jas2017.1927

16. Tobi EW, Goeman JJ, Monajemi R, et al. DNA methylation signatures link prenatal famine exposure to growth and metabolism. Nat Commun. 2014;5:5592. doi:10.1038/ncomms6592

17. Fu Q, Yu X, Callaway CW, Lane RH, McKnight RA. Epigenetics: intrauterine growth retardation (IUGR) modifies the histone code along the rat hepatic IGF-1 gene. FASEB J. 2009;23:24382449. doi:10.1096/fj.08-124768

18. McGee M, Bainbridge S, Fontaine-Bisson B. A crucial role for maternal dietary methyl donor intake in epigenetic programming and fetal growth outcomes. Nutr Rev. 2018;76:469-478. doi:10.1093/nutrit/nuy006

19. Hofstee P, McKeating DR, Perkins AV, Cuffe JS. Placental adaptations to micronutrient dysregulation in the programming of chronic disease. Clin Exp Pharmacol Physiol. 2018;45:871-884. doi:10.1111/1440-1681.12954

20. Liu HY, Liu SM, Zhang YZ. Maternal folic acid supplementation mediates offspring health via DNA methylation. Reprod Sci. 2020;27:963-976. doi:10.1007/s43032-020-00161-2

21. Sinclair KD, Allegrucci C, Singh R, et al. DNA methylation, insulin resistance, and blood pressure in offspring determined by maternal periconceptional B vitamin and methionine status. Proc Natl Acad Sci U S A. 2007;104:19351-19356. doi:10.1073/ pnas.0707258104

22. Maloney CA, Hay SM, Reid MD, et al. A methyl-deficient diet fed to rats during the pre- and peri-conception periods of development modifies the hepatic proteome in the adult offspring. Genes Nutr. 2013;8:181-190. doi:10.1007/s12263-012-0314-6

23. Oster M, Nuchchanart W, Trakooljul N, et al. Methylating micronutrient supplementation during pregnancy influences foetal hepatic gene expression and IGF signalling and increases foetal weight. Eur J Nutr. 2016;55:1717-1727. doi:10.1007/s00394-015-0990-2

24. Bonilla L, Luchini D, Devillard E, Hansen PJ. Methionine requirements for the preimplantation bovine embryo. J Reprod Dev. 2010;56:527-532. doi:10.1262/jrd.10-037h

25. Kudo M, Ikeda S, Sugimoto M, Kume S. Methionine-dependent histone methylation at developmentally important gene loci in mouse preimplantation embryos. J Nutr Biochem. 2015;26:16641649. doi:10.1016/j.jnutbio.2015.08.009

26. Acosta DAV, Denicol AC, Tribulo P, et al. Effects of rumenprotected methionine and choline supplementation on the preimplantation embryo in Holstein cows. Theriogenology. 2016;85:1669-1679. doi:10.1016/j.theriogenology.2016.01.024

27. Estrada-Cortés E, Negrón-Peréz VM, Tríbulo P, Zenobi MG, Staples CR, Hansen PJ. Effects of choline on the phenotype of the cultured bovine preimplantation embryo. J Dairy Sci. 2020;103:10784-10796. doi:10.3168/jds.2020-18598

28. Ishitani H, Ikeda S, Egashira K, et al. Embryonic MTHFR contributes to blastocyst development. J Assist Reprod Genet. 2020;37:1807-1814. doi:10.1007/s10815-020-01898-0

29. Caudill MA. Pre- and postnatal health: evidence of increased choline needs. J Am Diet Assoc. 2010;110:1198-1206. doi:10.1016/j.jada.2010.05.009

30. Freedman R, Hunter SK, Law AJ, Clark AM, Roberts A, Hoffman MC. Choline, folic acid, Vitamin D, and fetal brain development in the psychosis spectrum. Schizophr Res. Forthcoming 2021. doi:10.1016/j.schres.2021.03.008

31. Tríbulo P, Balzano-Nogueira L, Conesa A, Siqueira LG, Hansen PJ. Changes in the uterine metabolome of the cow during the first 7 days after estrus. Mol Reprod Dev. 2019;86:75-87. doi:10.1002/mrd.23082

32. Block J, Bonilla L, Hansen PJ. Efficacy of in vitro embryo transfer in lactating dairy cows using fresh or vitrified embryos produced in a novel embryo culture medium. J Dairy Sci. 2010;93:5234-5242. doi:10.3168/jds.2010-3443

33. Meissner A, Mikkelsen TS, Gu H, et al. Genome-scale DNA methylation maps of pluripotent and differentiated cells. Nature. 2008;454:766-770. doi:10.1038/nature07107

34. Krueger F, Andrews SR. Bismark: a flexible aligner and methylation caller for Bisulfite-Seq applications. Bioinformatics. 2011;27:1571-1572. doi:10.1093/bioinformatics/btr167

35. Akalin A, Kormaksson M, Li S, et al. MethylKit: a comprehensive $\mathrm{R}$ package for the analysis of genome-wide DNA methylation profiles. Genome Biol. 2012;13:R87. doi:10.1186/gb-2012-13-10-r87

36. Wang HQ, Tuominen LK, Tsai CJ. SLIM: a sliding linear model for estimating the proportion of true null hypotheses in datasets with dependence structures. Bioinformatics. 2011;27:225231. doi:10.1093/bioinformatics/btq650

37. Hansen PJ. Implications of assisted reproductive technologies for pregnancy outcomes in mammals. Annu Rev Anim Biosci. 2020;8:395-413. doi:10.1146/annurev-animal-021419-084010 
38. Hansen PJ, Dobbs KB, Denicol AC, Siqueira LGB. Sex and the preimplantation embryo: implications of sexual dimorphism in the preimplantation period for maternal programming of embryonic development. Cell Tissue Res. 2016;363:237-247. doi:10.1007/s00441-015-2287-4

39. Toledo MZ, Baez GM, Garcia-Guerra A, et al. Effect of feeding rumen-protected methionine on productive and reproductive performance of dairy cows. PLOS ONE. 2017;12:e189117. doi:10.1371/journal.pone.0189117

40. Ardalan M, Rezayazdi K, Dehghan-Banadaky M. Effect of rumen-protected choline and methionine on physiological and metabolic disorders and reproductive indices of dairy cows. J Anim Physiol Anim Nutr. 2010;94:e259-e265. doi:10.1111/j.1439-0396.2009.00966.x

41. Chaillou T, Kirby TJ, McCarthy JJ. Ribosome biogenesis: emerging evidence for a central role in the regulation of skeletal muscle mass. J Cell Physiol. 2014;229:1584-1594. doi:10.1002/jcp.24604

42. Zhang B, Denomme MM, White CR, et al. Both the folate cycle and betaine-homocysteine methyltransferase contribute methyl groups for DNA methylation in mouse blastocysts. FASEB J. 2015;29:1069-1079. doi:10.1096/fj.14-261131

43. Figueiredo VC, D'Souza RF, Van Pelt DW, et al. Ribosome biogenesis and degradation regulate translational capacity during muscle disuse and reloading. J Cachexia Sarcopenia Muscle. 2021;12:130-143. doi:10.1002/jcsm.12636

44. Santoro R, Grummt I. Molecular mechanisms mediating methylation-dependent silencing of ribosomal gene transcription. Mol Cell. 2001;8:719-725. doi:10.1016/s1097-2765(01)00317-3

45. von Walden F. Ribosome biogenesis in skeletal muscle: coordination of transcription and translation. J Appl Physiol. 2019;127:591-598. doi:10.1152/japplphysiol.00963.2018

46. Bernadzki KM, Gawor M, Pęziński M, et al. Liprin- $\alpha-1$ is a novel component of the murine neuromuscular junction and is involved in the organization of the postsynaptic machinery. Sci Rep. 2017;7:9116. doi:10.1038/s41598-017-09590-7

47. Yadav VR, Song T, Mei L, Joseph L, Zheng YM, Wang YX. PLC $\gamma 1-$ $\mathrm{PKC} \varepsilon-\mathrm{IP}_{3} \mathrm{R} 1$ signaling plays an important role in hypoxiainduced calcium response in pulmonary artery smooth muscle cells. Am J Physiol Lung Cell Mol Physiol. 2018;314:L724-L735. doi:10.1152/ajplung.00243.2017

48. Cruickshank MN, Oshlack A, Theda C, et al. Analysis of epigenetic changes in survivors of preterm birth reveals the effect of gestational age and evidence for a long term legacy. Genome Med. 2013;5:96. doi:10.1186/gm500

49. Hoyo C, Murtha AP, Schildkraut JM, et al. Methylation variation at IGF2 differentially methylated regions and maternal folic acid use before and during pregnancy. Epigenetics. 2011;6:928936. doi:10.4161/epi.6.7.16263

50. Vineis P, Chuang SC, Vaissière $\mathrm{T}$, et al. DNA methylation changes associated with cancer risk factors and blood levels of vitamin metabolites in a prospective study. Epigenetics. 2011;6:195-201. doi:10.4161/epi.6.2.13573

51. Kovacheva VP, Mellott TJ, Davison JM, et al. Gestational choline deficiency causes global and Igf2 gene DNA hypermethylation by up-regulation of Dnmt1 expression. J Biol Chem. 2007;282:31777-31788. doi:10.1074/jbc.M705539200

52. Adam MA, Isles AR. EHMT1/GLP; biochemical function and association with brain disorders. Epigenomes. 2017;1:15. doi:10.3390/epigenomes1030015

53. Watson ZL, Yamamoto TM, McMellen A, et al. Histone methyltransferases EHMT1 and EHMT2 (GLP/G9A) maintain PARP inhibitor resistance in high-grade serous ovarian carcinoma. Clin Epigenetics. 2019;11:165. doi:10.1186/s1314 8-019-0758-2

54. Williams TC, Drake AJ. Preterm birth in evolutionary context: a predictive adaptive response? Philos Trans $R$ Soc Lond B Biol Sci. 2019;15:1770. doi:10.1098/rstb.2018.0121

55. Wood CE. Control of parturition in ruminants. J Reprod Fertil Suppl. 1999;54:115-126.

56. Jiang X, Yan J, West AA, et al. Maternal choline intake alters the epigenetic state of fetal cortisol-regulating genes in humans. FASEB J. 2012;26:3563-3574. doi:10.1096/fj.12-207894

57. Burns BM, Hiendleder S, Laing AR, Fordyce G, Herring AD. Ultrasonographic measurements in first trimester concepti identify predictors of birth weight and postnatal development in cattle. J Anim Sci. 2018;96:4186-4194. doi:10.1093/jas/ sky290

\section{SUPPORTING INFORMATION}

Additional Supporting Information may be found online in the Supporting Information section.

How to cite this article: Estrada-Cortés E, Ortiz W, Rabaglino MB, et al. Choline acts during preimplantation development of the bovine embryo to program postnatal growth and alter muscle DNA methylation. FASEB J. 2021;35:e21926. https://doi. org/10.1096/fj.202100991R 